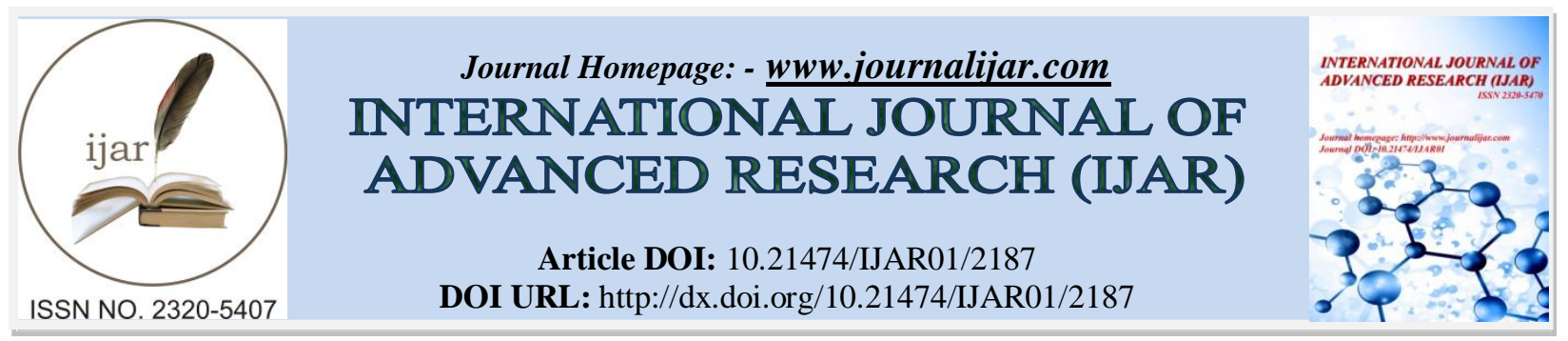

RESEARCH ARTICLE

\title{
STUDY OF RELATIONSHIP BETWEEN TYPE 2 DIABETES MELLITUS AND FUNCTIONAL HYPOPARATHYROIDISM.
}

\section{Mohamed Yehia Seddek, Mohamed Shawky El-sayed, Ayman El-Badawy and Mohammed Abd Elaal El Sha3er.}

Internal medicine department,Faculty of medicine, Banha University ,Qalyubia, Egypt.

\section{Manuscript Info}

Manuscript History

Received: 27 September 2016

Final Accepted: 30 October 2016

Published: November 2016

\section{Abstract}

Background \& Aims:- Themetabolic derangement caused by diabetes mellitus may potentiallyaffect bone mineral metabolism. In the present study we evaluatedthe effect of diabetes metabolic control on parathyroid hormone (PTH) secretion.

Methods:- This study included 30 patients who had type 2 diabetes who attended outpatients' clinic Fasting blood glucose, HbA1c, calcium, phosphorus, magnesium, creatinine, parathormonelevels were studied for each patient.

Results:- Patients with impaired blood sugar regulation (HbA1c $>10 \%$ ) had lower levels of PTH, albumin and 25(OH)D levels and higher phosphorus levels.

compared to patients with HbA1c levels below $10 \% \quad(\mathrm{p}=0.018$, $\mathrm{p}=0.043, \mathrm{p}=0.002, \mathrm{p}=0.01$, respectively. Among the diabetic patients, magnesium levels were significantly lower in those with functional hypoparathyroidism (parathormone $<65 \mathrm{ng} / \mathrm{mL}$ ) compared to those with secondary hyperparathyroidism . Comparative statistical analysis of patients with $\mathrm{HbA} 1 \mathrm{c}$ levels above and below $10 \%$ demonstrated higher proportion of patients with functional hypoparathyroidism in the group with impaired blood sugar regulation).

Conclusions:- increased frequency of functional hypoparathyroidism inpatients with type 2 diabetes mellitus with impaired blood sugar regulation.

Copy Right, IJAR, 2016,. All rights reserved.

\section{Introduction:-}

Diabetes mellitus is the fifth leading cause of death in modern countries and it is a major cause of significant morbidit.Identification of environmental and easily-modified risk factors is urgently needed to prevent development of diabetseirtnuoc depoleved ni hti.setebaid fo tnempoleved tnevees. Poor metabolic control of diabetes mellitus can induce alterations in calcium homeostasis (Seino et al., 1995).

As a consequence, an increase in parathyroid hormone (PTH) secretion may occur to correct for any possibility of reduction in calcium. However, the complete disturbance of mineral metabolism observed in diabetes mellitus also involves alterations in magnesium homeostasis, with an impaired parathyroid hormone response to calcium wastage. Interest in the evaluationof mineral metabolism observed in diabetic patientshas increased since the reports of an association between diabetes mellitus with osteopenia development. Seino and Ishida reviewed several points concerning osteopenia and diabetes: a) urinary waste of calcium ,phosphorus and magnesium is correlated with the 
intensity of glycosuria.(Mc Nair et al., 1982) have shown that serum calcium and PTH are slightly lower in diabetics than in control : b) with respect to vitamin D metabolism reported that $1,25(\mathrm{OH}) 2 \mathrm{D}$ levels are lower in diabetic patients, (Frazer et al., 1981).

Thus, the major objective of the present study is to evaluate PTH secretion in type 2 diabetic patients with different degrees of metabolic control.

\section{Material and Methods:-}

\section{Patients:-}

This study will be conducted on patients with type 2 diabetes mellitus and apparently healthy volunteers working as a control . Diabetic patients will be selected from those attending out patient clinic at Benha University Hospital .

\section{Inclusion Criteria:-}

- Patients with type 2 diabetes mellitus.

\section{Exclusion Criteria:-}

- Diabetic patients with nephropathy

- Diabetic patients with malapsorption or diarrhea

- Patients with primary hyperparathyroidism.

- Patients with type2 diabetes receiving calcium and /or vitamin D. or any drug that might affect $\mathrm{Ca}, \mathrm{Mg}$ metabolism

\section{Methods:-}

All patients of this study will submit to the following:

1. Full medical history.

2. Thorough medical examination.

3. Laboratory investigation:

4. Fasting blood glucose,Hb A1C,Parathormone level,Serum Calcium, Magnesium, Phosphorus

\section{Results:-}

Socio-demographic characters of the studied sample.

\begin{tabular}{|l|l|l|l|}
\hline Variable & No. $(\mathbf{N}=\mathbf{4 5})$ & \% (100\%) \\
\hline \multirow{3}{*}{ The studied groups } & Patients & 25 & 55.6 \\
\cline { 2 - 4 } & Controls & 20 & 44.4 \\
\hline \multirow{2}{*}{ Sex } & Male & 27 & 60.0 \\
\cline { 2 - 4 } & Female & 18 & 40.0 \\
\hline
\end{tabular}

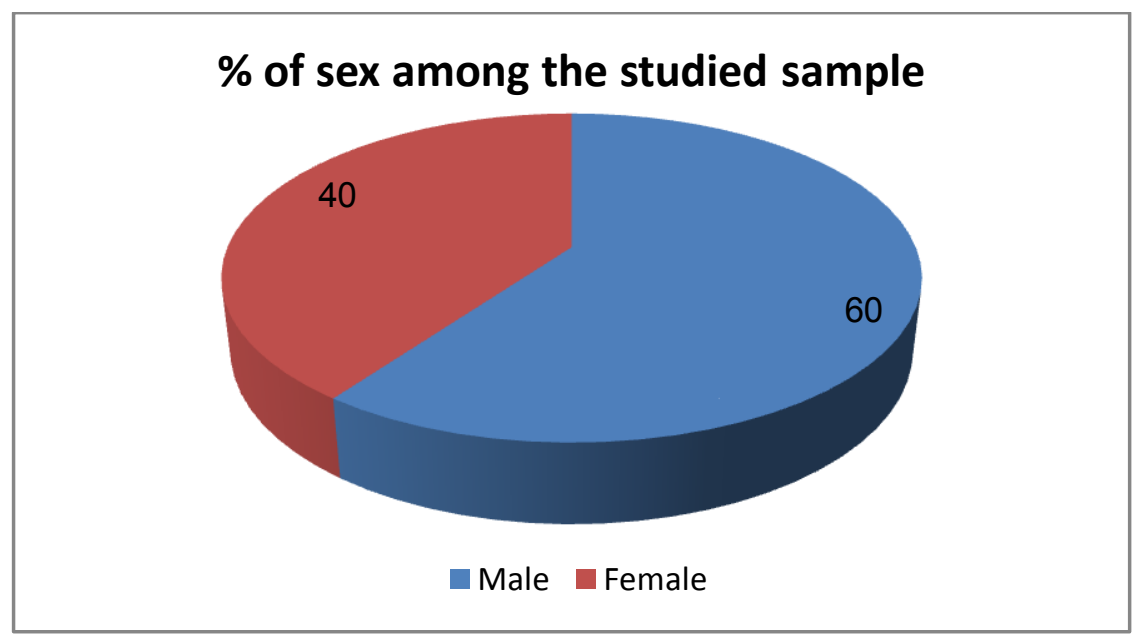


Comparing the studied groups regarding PTH level.

\begin{tabular}{|l|l|l|l|l|l|l|}
\hline Group & \multirow{2}{*}{ n. } & \multicolumn{2}{|l|}{ PTH } & St."t" & P \\
\cline { 3 - 5 } & & Mean & $\mathbf{\pm S D}$ & Range & & \\
\hline Patients (HbA1c >7\%) & $\mathbf{2 5}$ & 30.7 & 10.36 & $12.1-46$ & 7.54 & $<0.001$ \\
\hline Controls (HbA1c <7\%) & $\mathbf{2 0}$ & 54.0 & 10.20 & $36-66$ & & $(\mathrm{HS})$ \\
\hline
\end{tabular}

Comparing the studied groups regarding HbA $1 \mathrm{C}$ level.

\begin{tabular}{|l|l|l|l|l|l|l|}
\hline \multirow{2}{*}{ Group } & $\mathbf{n}$. & \multicolumn{2}{|l|}{ HbA1C } & Z & of & P \\
\cline { 3 - 6 } & & Mean & $\mathbf{\pm S D}$ & Range & MWU & \\
\hline Patients & $\mathbf{2 5}$ & 10.3 & 1.80 & $8.2-14$ & 5.71 & $<0.001$ \\
\hline Controls & $\mathbf{2 0}$ & 4.9 & 0.54 & $4.3-6$ & & $(\mathrm{HS})$ \\
\hline
\end{tabular}

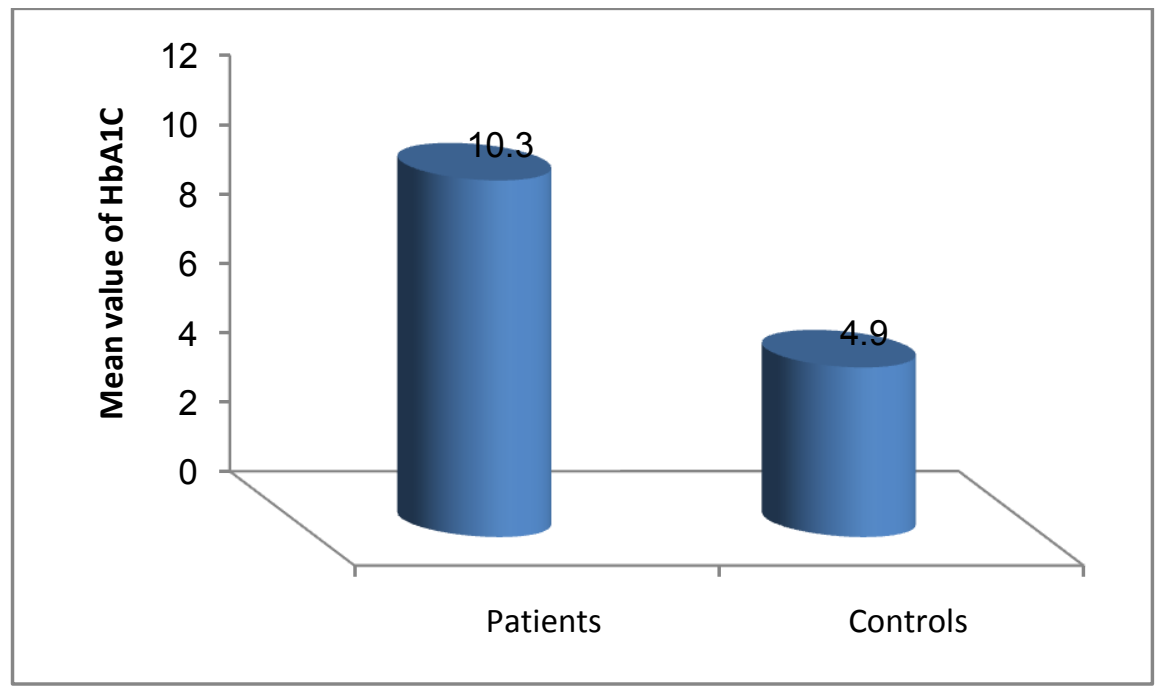

Comparing the studied groups regarding serum manesium level.

\begin{tabular}{|l|l|l|l|l|l|l|}
\hline Group & $\mathbf{n}$. & \multicolumn{2}{|l|}{ Serum magnesium } & \multirow{2}{*}{ Z of MWU } & P \\
\cline { 3 - 5 } & & Mean & $\mathbf{\pm S D}$ & Range & & \\
\hline Patients & $\mathbf{2 5}$ & 1.91 & 0.36 & $1.4-2.9$ & 2.15 & 0.032 \\
\hline Controls & $\mathbf{2 0}$ & 2.09 & 0.18 & $1.8-2.4$ & & $(\mathrm{~S})$ \\
\hline
\end{tabular}

PTH level according to HbA1c among the patients group

\begin{tabular}{|l|l|l|l|l|l|l|}
\hline HbA1C & $\mathbf{n}$. & \multicolumn{2}{|l|}{ PTH } & St. "t" & P \\
\cline { 3 - 5 } & & Mean & $\mathbf{\pm}$ SD & Range & & \\
\hline$<\mathbf{1 0 \%}$ & $\mathbf{1 4}$ & 35.9 & 7.33 & $18-45.9$ & 3.44 & 0.002 \\
\hline$>\mathbf{1 0 \%}$ & $\mathbf{1 1}$ & 24.03 & 10.01 & $12.1-46$ & & $(\mathrm{~S})$ \\
\hline
\end{tabular}

Correlation between PTH level and the studied variables among the patients group (HbA1c>7\%).

\begin{tabular}{|l|l|l|}
\hline \multirow{2}{*}{ With } & $\begin{array}{l}\text { PTH } \\
(\mathrm{n}=25)\end{array}$ & $\mathrm{P}$ \\
\cline { 2 - 3 } & rho & $<0.001(\mathrm{HS})$ \\
\hline HbA1C & -0.750 & $0.27(\mathrm{NS})$ \\
\hline Creatinine & -0.167 & $0.044(\mathrm{~S})$ \\
\hline S. calcium & -0.407 & $0.004(\mathrm{~S})$ \\
\hline S. magnesium & 0.421 & \\
\hline
\end{tabular}



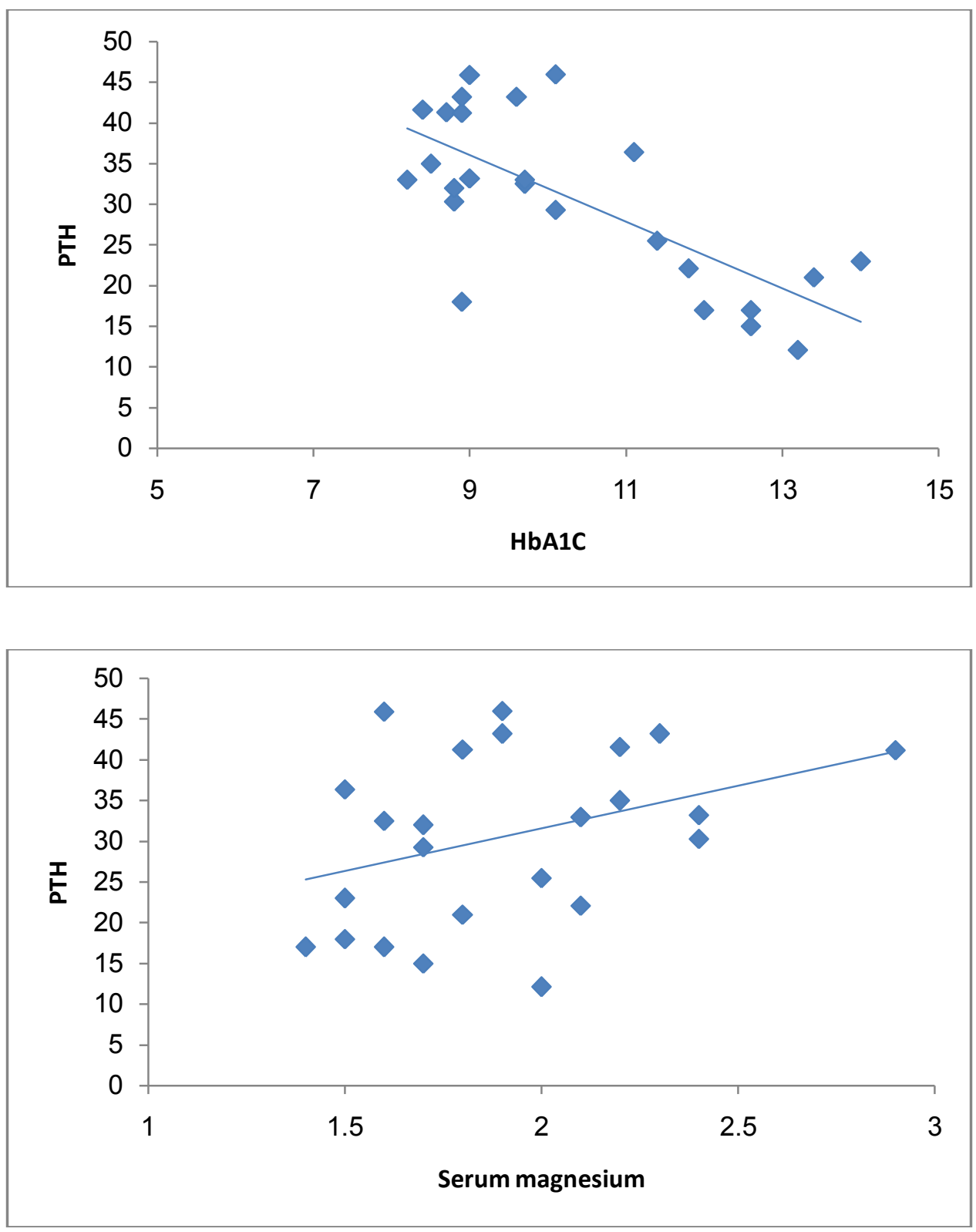

Correlation between PTH level and the studied variables according to HbA1c level among the patients group.

\begin{tabular}{|c|c|c|c|c|}
\hline \multirow[t]{3}{*}{ With } & \multicolumn{4}{|l|}{ PTH } \\
\hline & \multicolumn{2}{|c|}{$\begin{array}{l}\mathrm{HbA1C}<10 \\
(\mathrm{n}=14)\end{array}$} & \multicolumn{2}{|c|}{$\begin{array}{l}\mathrm{HbA1C}>10 \\
(\mathrm{n}=11)\end{array}$} \\
\hline & rho & $\mathrm{P}$ & rho & $\mathrm{P}$ \\
\hline $\mathrm{HbA1C}$ & -0.046 & $0.88(\mathrm{NS})$ & -0.693 & $0.018(\mathrm{~S})$ \\
\hline Creatinine & -0.149 & 0.61 (NS) & 0.028 & 0.93 (NS) \\
\hline S. calcium & -0.066 & $0.82(\mathrm{NS})$ & -0.231 & $0.49(\mathrm{NS})$ \\
\hline S. magnesium & 0.153 & 0.6 (NS) & -0.009 & 0.98 (NS) \\
\hline
\end{tabular}




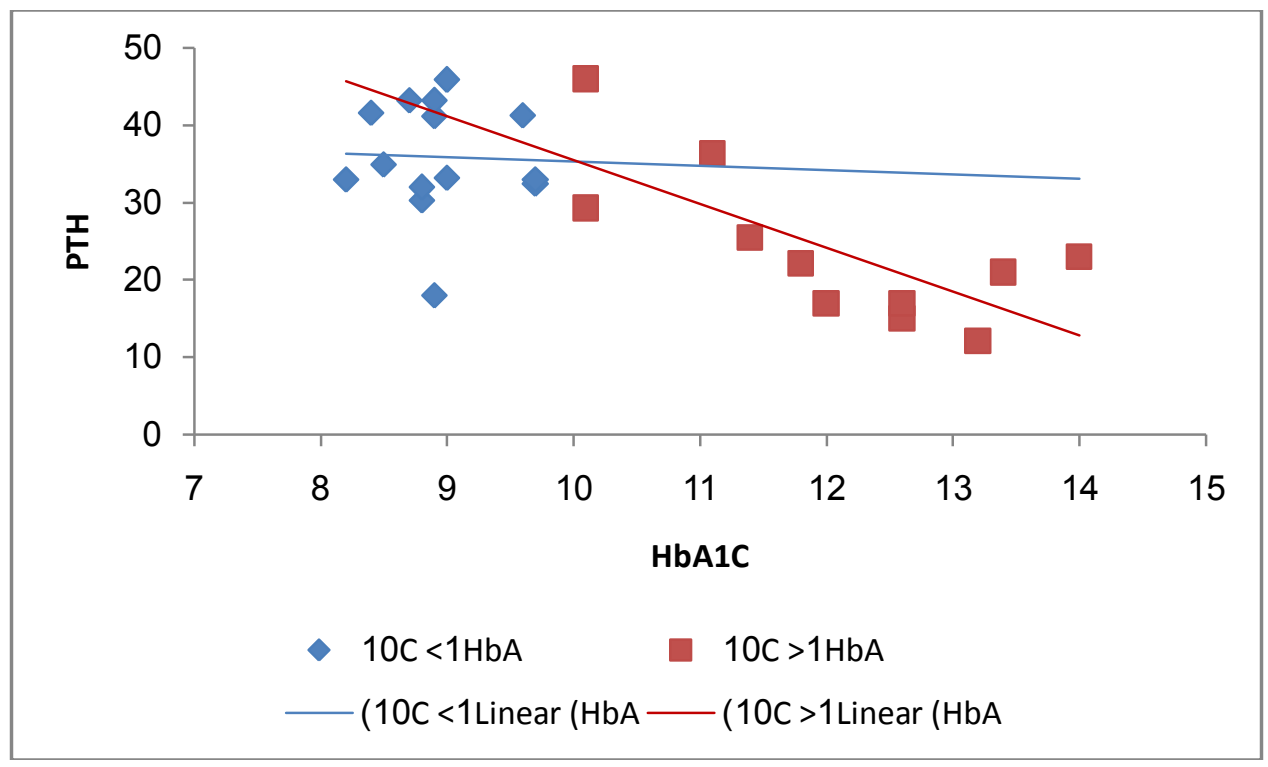

Multiple linear regression analysis for the predictors of PTH level among diabetic patients.

\begin{tabular}{|c|c|c|c|c|c|}
\hline \multirow[t]{2}{*}{ Model summary } & $\mathbf{R}^{2}$ & Adjusted R ${ }^{2}$ & SEE & $F_{(3,21)}$ & P-value \\
\hline & 0.554 & 0.480 & 7.47 & 8.39 & 0.001 (HS) \\
\hline Variable & $\mathbf{b}_{0}$ & b & $95 \%$ CI of $b$ & t & $\mathbf{P}$ \\
\hline HbA1C & \multirow[t]{3}{*}{98.06} & -4.26 & $\begin{array}{l}-6.3- \\
(-2.23)\end{array}$ & 4.36 & $<0.001(\mathrm{HS})$ \\
\hline S. calcium & & -3.65 & $\begin{array}{l}-10.04- \\
2.73\end{array}$ & 1.19 & $\begin{array}{l}0.27 \\
\text { (NS) }\end{array}$ \\
\hline S. magnesium & & 5.0 & $\begin{array}{l}-5.9- \\
15.9\end{array}$ & 0.95 & $\begin{array}{l}0.35 \\
\text { (NS) }\end{array}$ \\
\hline
\end{tabular}

Factors found to be significantly correlated with PTH were entered the multiple linear regression model to detect the significant predictors of PTH among diabetic patients, it was found that only HbA1C is the significant predictor.

\section{Discussion:-}

For type 2 diabetes mellitus to occur, both insulin resistance and inadequate insulin secretion must exist. For example, all overweight individuals have insulin resistance, but diabetes develops only in those who cannot increase insulin secretion sufficiently to compensate for their insulin resistance. Their insulin concentrations may be high, yet inappropriately low for the level of glycemia. With prolonged diabetes, atrophy of the pancreas may occur. A study by Philippe et al used computed tomography (CT) scan findings, glucagon stimulation test results, and fecal elastase-1 measurements to confirm reduced pancreatic volume in individuals with a median 15-year history of diabetes mellitus (range, 5-26 years). This may also explain the associated exocrine deficiency seen in prolonged diabetes(Philippe et al., 2011).

The metabolic derangement caused by diabetes mellitus may potentially affect bone mineral metabolism. In the present study we evaluated the effect of diabetes metabolic control on parathyroid hormone(PTH) secretion. Poor metabolic control of diabetes mellitus can induce alterations in calcium homeostasis. As a consequence, an increase in parathyroid hormone (PTH) secretion may occur to correct for any possibility of a reduction in calcium. (Seino et al., 1995 ).However, the complete disturbance of mineral metabolism observed in diabetes mellitus also involves alterations in magnesium homeostasis, with an impaired parathyroid response to calcium wastage. Interest in the evaluation of mineral metabolism in diabetics has increased since the reports of an association of diabetes mellitus with osteopenia development(Forsen et al., 1999 ). Conflicting results have been reported about the relationship between diabetes and fractures but recent population-based studies have shown that diabetes is a risk factor for hip, proximal humerus and foot fractures among older women (Schwartz et al., 2001).it is well known that alterations in mineral metabolism can induce disturbance in glucose metabolism (Rosolova et al ., 1997 ) and glucose intolerance which also can interfere with mineral metabolism. Previous studies have shown that poor diabetes mellitus control is 
associated with calcium, phosphorus and magnesium wastage. We evaluated PTH secretion in diabetic patients with different degrees of metabolic control and our results showed that patients with poor metabolic control present lower PTH secretion than well-controlled diabetic and normal subjects during acute stimulation( Liu et al., 2003 ).In our poorly-controlled diabetic patients $(\mathrm{HbA} 1 \mathrm{c}>10$ parathormone levels as well as vitamin D levels were lower compared to those with HbA1c levels $<10 \%$ ( $\mathrm{p}=0.018$ ). This was probably associated with the effect of hyperglycemia and/or glycosuria on calcium metabolism. Sugimoto et al. demonstrated that glucose at high concentrations inhibited parathormone secretion in bovine parathyroid cell culture. This in vitro evidence was later supported by several clinical studies. For example, Polymeris et al. reported parathormone reduction, which was negatively correlated with increases in blood glucose levels, during oral glucose tolerance test in non-diabetic postmenopausal women (Polymeris et al., 2011).Besides impaired blood sugar regulation, magnesium loss developing during osmotic diuresis secondary to glycosuria is another mechanism held responsible for impaired parathormone secretion in patients with type 1 diabetes mellitus. As such, chronic magnesium deficiency impairs parathormonerelease, resulting in functional hypoparathyroidism. In a study by Sagesse et al. in patients with type 1 diabetes mellitus, magnesium replacement resulted in increased parathormone levels, which is supportive of the above evidence. Similarly, Paula et al. demonstrated blunted parathormone responses to hypocalcemia induced by EDTA infusion in most type 1 diabetes mellitus patients with poor metabolic control. This study also determined low serum magnesium levels in poorly-controlled diabetic patients compared to controls (Paula et al., 2001 ).

Our results are in accordance with those reported by Rude et al. i.e., normal basal PTH levels in subjects with magnesium higher than $0.44 \mathrm{mmol} / \mathrm{l}$. Furthermore, we observed that the parathyroid response to acute hypocalcemia is impaired in diabetic patients with serum magnesium levels of $0.64 \pm 0.03 \mathrm{mmol} / \mathrm{l}$.

The action of PTH favoring the maintenance and/or increase in bone mass may be secondary to its metabolic actions of urine calcium retention and/or to increased intestinal calcium absorption secondary to stimulation of 1,25(OH)2D synthesis or may even be due to a direct activation of osteoblasts, in view of the fact that previous studies have shown PTH receptors in these cells (McSheehy et al ., 1986).

Our results clearly show that PTH secretion is impaired in patients with poorly controlled diabetes mellitus and suggest an association between this occurrence and the low serum levels of magnesium observed in these patients. Previous studies have suggested that the osteopenia observed in diabetic patients is due to the reduction in $1,25(\mathrm{OH}) 2 \mathrm{D}$ levels and that insulin deficiency could reduce osteoblast activity(UK Prospective Diabetes Study (UKPDS)Group (1998).)However, other studies have suggested that osteopenia is not a complication of diabetes mellitus .Probably, both hypotheses can be considered true in view of theheterogeneous situation of diabetes mellitus(Van Daele et al., 1995). Whereas patients with good metabolic control have normal calcium ion and PTH secretion, poorly controlled diabetics tend to present lower calcium ion levels, deficient PTH secretion and lower serum magnesium levels. Thus, on the basis of these alterations, it is possible that osteopenia is a nonclassical complication of diabetes which is likely to be related to hyperglycemia In our study, the frequency of functional hypoparathyroidism was higher in patients with impaired blood sugar regulation (HbA1c >10). Magnesium levels were also lower in these patients with functional hypoparathyroidism. This finding was consistent with functional hypoparathyroidism resulting from osmotic diuresis due to glycosuria in patients with type 1 diabetes(Yamaguchi et al ., 2011).

\section{Conclusion:-}

our study is important to demonstrate the increased frequency of functional hypoparathyroidism inpatients with type 2 diabetes mellitus with impaired blood sugar regulation, which was described previously for patients with type 1 diabetes mellitus. This should be evaluated by further studies to investigate the effects on bone loss and fragility in patients with type 2 diabetes mellitus. 


\section{References:-}

1. Seino Y \& Ishida H (1995). Diabetic osteopenia.Pathophysiology and clinical aspects.Diabetes and Metabolism Reviews, 11: 21-35.

2. McNair P, Madsbad S, Christiansen C, Christensen MS \&Transbal I (1982). Hyponatremia and hyperkalemia in relation to hyperglycemia in insulin treated diabetic out-patients. ClinicaChimicaActa, 120: 243-250.

3. Frazer TE, White NH, Hough S, Santiago JV, McGee BR, Bryle O, Mallon J \&AvioliLV (1981). Alterations in circulating vitamin D metabolites in the young insulindependentdiabetic.Journal of ClinicalEndocrinology and Metabolism, 53: 1154- 1159..

4. Schwartz AV, Sellmeyer DE, Ensrud KE, Cauley JA, Tabor HK, Schreiner PJ, Jamal SA, Black DM \& Cummings SR (2001). Older women with diabetes have an increased risk of fracture: a prospective study. Journal of Clinical Endocrinologyand Metabolism, 86: 32-38.

5. ForsenL, Meyer HE, Midthjell K \& Edna TH (1999). Diabetes mellitus and the incidence of hip fracture: results from the Nord-Trondelag health survey. Diabetologia, 42: 920-925

6. Rosolova H, Mayer O \&Reaven G (1997). Effect of variation in plasma magnesium concentration on resistance to insulinmediated glucose disposal in nondiabeticsubjects.Journal of Clinical Endocrinologyand Metabolism, 82: 3783-3785 7. UK Prospective Diabetes Study (UKPDS) Group (1998). Intensive blood-glucose control with sulfonylureas or insulin compared with conventional treatment and risk of complications in patients with type 2 diabetes (UKPDS 33). Lancet, 352: 837- 853.

7. Rude RK (1996). Magnesium depletion and hypermagnesemia. In: Favas MJ (Editor), Primer on the Metabolic Bone Diseasesand Disorders of Mineral Metabolism. 3rd edn.Lippincot-Raven, Philadelphia

8. Lima ML, Rodrigues LE, Cruz T, Barbosa K, Pousada CP \&Canguçu V (1998). The effect of magnesium supplementation in increasing doses on the control of type 2

9. diabetes. Diabetes Care, 21: 682-686.

10. Brown EM \&Pollak Hebert SC (1998). The extracellular calcium-sensing receptor: its role in health and disease. AnnualReview of Medicine, 49: 15-29.

11. Van Daele PLA, Stolk RP, Burger H, AlgraD, Grobbee DE, Hofman AP, BirkenhagerJP \&Huibert AP (1995). Bone density in non-insulin-dependent diabetes mellitus.The Rotterdam Study.Annals of InternalMedicine, 122: 409-414.

12. McSheehy PHJ \& Chambers TJ (1986). Osteoblastic cells mediate osteoclasticresponsiveness to PTH. Endocrinology, 118: 824-828.

13. Garton M, Martin J, Stewart A, KrukowskiZ, Matheson N, Robins S, Lowredge N \&Reid D (1995). Changes in bone mass and metabolism after surgery for primary hyperparathyroidism.Clinical Endocrinology, 42: 493-500.

14. Paula FJ, Lanna CM, Shuhama T, Foss MC. Effect of metabolic control on \parathyroid hormone secretion in diabetic patients.Braz J Med Biol Res 2001;34:1139-1145

15. Yamaguchi T, Kanazawa I, Takaoka S, Sugimoto T. Serum calcium is positively correlated with fasting plasma glucose and insulin resistance, independent of parathyroid hormone, in male patients with type 2 diabetes mellitus. Metabolism 2011;60:1334-1339.

16. Polymeris AD, Doumouchtsis KK, Giagourta I, Karga H. Effect of an oral glucose load on PTH, 250HD3, calcium, and phosphorus homeostasis in postmenopausal women. Endocr Res 2011;36:45-52.

17. Sugimoto T, Ritter C, Morrissey J, Hayes C,Slatopolsky E. Effects of high concentrations of glucose on PTH secretion in parathyroid cells. Kidney Int1990;37:1522-1527. 